\title{
POLÍTICAS PÚBLICAS E DESENVOLVIMENTO SUSTENTÁVEL: REFLEXÕES SOBRE A DIMENSÃO SOCIAL DA SUSTENTABILIDADE
}

\section{POLÍTICAS PÚBLICAS Y DESARROLLO SOSTENIBLE: REFLEXIONES SOBRE LA DIMENSIÓN SOCIAL DE LA SOSTENIBILIDAD}

\section{PUBLIC POLICY AND SUSTAINABLE DEVELOPMENT: REFLECTIONS ON THE SOCIAL DIMENSION OF SUSTAINABILITY}

\author{
Bruno Ferreira SOARES ${ }^{1}$ \\ Suely Salgueiro CHACON ${ }^{2}$ \\ Verônica Salgueiro do NASCIMENTO ${ }^{3}$ \\ João César Abreu de OLIVEIRA ${ }^{4}$
}

\begin{abstract}
RESUMO: As reflexões em torno dos elementos contidos no tema desenvolvimento sustentável remontam a década de 1950, no entanto, o surgimento desse conceito é relativamente recente, datando de 1987 quando Gro Harlem Brundtland, apresentou os resultados do relatório "Nosso Futuro Comum" à Assembleia Geral da Organização das Nações Unidas - ONU. Tem como ponto central a ideia de um crescimento econômico eficiente e racional, que satisfaça as necessidades das gerações presentes sem comprometer o direito das gerações futuras em ter suas necessidades supridas. Percebe-se que o conceito de desenvolvimento sustentável - motivo cada vez maior de revisões críticas - nos dias atuais, ainda está popularmente ligado simplesmente aos aspectos ambientais, e as políticas públicas de desenvolvimento adotadas, via de regra, restringem-se à perspectiva econômica. $\mathrm{O}$ presente ensaio propõe-se a refletir sobre os aspectos relacionados às dimensões da sustentabilidade propostas por Ignacy Sachs (1993), com foco especial para a dimensão social. Para tanto, utilizou-se como metodologia a revisão literária das contribuições de Richard Sennett (2012), Hassan Zaoual (2006), Milton Santos (2009), Paulo Freire (2013) e Suely Chacon (2007), adotando como premissa a negação dos elementos que comprometem esta dimensão.
\end{abstract}

Palavras-Chave: Desenvolvimento Sustentável; Políticas Públicas; Dimensão Social.

RESUMEN: Las reflexiones sobre los elementos contenidos en el tema de la fecha el desarrollo sostenible de regreso a la década de 1950, sin embargo, la aparición del concepto es

\footnotetext{
${ }^{1}$ Mestrando em Desenvolvimento Regional Sustentável pela Universidade Federal do Cariri - UFCA. E-mail: bruno.geografia@hotmail.com / Telefone: (88) 9939-4769

${ }^{2}$ Doutora em Desenvolvimento Sustentável pela Universidade de Brasília - UNB. Professora da Universidade Federal do Cariri - UFCA. E-mail: suelychacon@ gmail.com / Telefone: (88)3572-7234

3 Doutora em Educação Brasileira pela Universidade Federal do Ceará - UFC. Professora da Universidade Federal do Cariri - UFCA. E-mail: vesalgueiro@ufca.edu.br / Telefone: (88)3572-7234

${ }^{4}$ Doutor em Educação pela Universidade Federal do Ceará - UFC. Professor da Universidade Regional do Cariri - URCA e do Instituto Federal de Educação, Ciência e Tecnologia do Ceará - IFCE. E-mail: njcesar@bol.com.br / Telefone: (88) 8801-3543
} 
relativamente nuevo, que data de 1987, cuando Gro Harlem Brundtland, presentó los resultados del informe "Nuestro futuro común" a la Asamblea General Naciones Unidas ONU. Tiene como punto central la idea de un crecimiento económico eficiente y racional que satisfaga las necesidades de las generaciones actuales sin comprometer la capacidad de futuras generaciones para tener sus necesidades satisfechas. Se dio cuenta de que el concepto de desarrollo sostenible - razón más y más comentarios crítico - hoy en día, sigue siendo popularmente simplemente conectado a los aspectos ambientales, y las políticas públicas de desarrollo adoptados por regla general, restringido a las perspectivas econômicas. Este ensayo se propone reflexionar sobre los aspectos relacionados con las dimensiones de la sostenibilidad propuestos por Ignacy Sachs (1993), con especial atención a la dimensión social. Para esto, metodología se utilizó como una revista literaria de las contribuciones de Richard Sennett (2012), Hassan Zaoual (2006), Milton Santos (2009), Paulo Freire (2013) y Suely Chacón (2007), adoptando como premisa la negación de los elementos que comprometen esta dimensión.

Palabras clave: desarrollo sostenible; Políticas Públicas; Dimensión Social

\begin{abstract}
The reflections on the evidence on the sustainable development theme dating back to the 1950s, however, the emergence of the concept is relatively recent, dating back to 1987 when Gro Harlem Brundtland, presented the results the report "Our Common Future" at the United Nations General Assembly - UN. Its central point the idea of an efficient and rational economic growth that meets the needs of present generations without compromising the right of future generations to have their needs met. It is noticed that the concept of sustainable development - why increasing critical review - nowadays, is still popularly simply connected to the environmental aspects, and public development policies adopted as a rule, restricted to the economic outlook. This essay proposes to reflect on aspects related to the dimensions of sustainability proposed by Ignacy Sachs (1993), with special focus on the social dimension. For both, it was used as a methodology to review the literary contributions of Richard Sennett (2012), Hassan Zaoual (2006), Milton Santos (2009), Paulo Freire (2013) and Suely Chacon (2007), adopting as its premise the denial of elements which compromise this dimension.
\end{abstract}

Keywords: Sustainable Development; Public Policies; Social Dimension.

\title{
Introdução
}

O economista Ignacy Sachs possui uma histórica contribuição em relação aos elementos contidos na proposta de um desenvolvimento que seja ambientalmente correto ao mesmo tempo em que promova uma melhoria na qualidade de vida das pessoas. A preocupação com o papel do homem, a ética e o planejamento dentro de um projeto que vise à promoção de desenvolvimento está presente em toda a sua obra. Nesse sentido, o presente ensaio propõe- 
se a refletir sobre os aspectos relacionados às dimensões da sustentabilidade propostas por Ignacy Sachs (1993), com ênfase à dimensão social. Adota como premissa a negação dos elementos que comprometem a referida dimensão. Esta proposta se justifica pelo fato de que, mesmo com a questão social tendo sido motivo de preocupação junto com o impulso que as propostas de um desenvolvimento sustentável ganharam principalmente após a Conferência das Nações Unidas sobre Meio Ambiente e Desenvolvimento (CNUMD) em 1992, nos dias atuais, a imagem da sustentabilidade ainda estar popularmente associada a aspectos unicamente ambientais. Economia de água, reciclagem, combate ao desmatamento, redução da utilização de combustíveis fósseis, redução do consumo, entre outras, de fato, são ações inerentes à sustentabilidade, no entanto, muitas vezes a exclusão social e o aspecto humano dessa mesma sustentabilidade são esquecidos. Além disso, os modelos de políticas de desenvolvimento adotados, via de regra, não observam as especificidades locais dos territórios alvos de tais políticas, transformando os projetos em projéteis, atirados às comunidades. Para a reflexão em torno do que Sachs denomina como dimensão social da sustentabilidade, utilizou-se de uma revisão literária das contribuições de Richard Sennett (2012), Hassan Zaoual (2006), Milton Santos (2009), Paulo Freire (2013) e Suely Chacon (2007), tendo como pano de fundo a instigação reflexiva trazida pelo slogan do presidente norte americano Barack Obama em sua campanha eleitoral de 2008, quando o "Yes, We Can" tornou-se uma proposta de mudança para a política interna e externa daquele país.

\section{Algumas considerações sobre a biografia de Sachs}

Polonês de nascimento (Varsóvia - 1927), Ignacy Sachs chegou ao Brasil em 1941 fugindo da segunda guerra mundial, e do nazismo em especial, onde realizou seus estudos na Universidade de Ciências Políticas e Econômicas do Rio de Janeiro e permaneceu até 1954. Retornando à Polônia, Sachs foi pesquisador do Instituto Polonês de Assuntos Internacionais até 1957 quando passou a atuar como segundo secretário da embaixada polonesa na Índia (PEREIRA, 2013.p.361) e realizou seu Doutorado em economia pela Universidade de Delhi, em 1961.

De volta à Polônia, foi professor na Escola Central de Planejamento e Estatística de Varsóvia e diretor do Centro de Pesquisas em Economias em Desenvolvimento (MOURA, 2013.p.145). Em 1968, quando o antissemitismo voltara a tomar conta do seu país de nascença, Sachs novamente foi para o exílio, agora na França, onde se tornou professor da Escola de Estudos Avançados em Ciências Sociais - EHESS, fundou o Centro de Estudos 
Sobre o Brasil Contemporâneo (PEREIRA, 2013.p.362) e o Centro Internacional de Pesquisa sobre Meio Ambiente e Desenvolvimento - CIRED, em 1973.

Sachs participou da conferencia de Founex $^{5}$ em 1971 e dos preparativos para a conferencia de Estocolmo em 1972, também em 1972 dirigiu a missão CEPAL/PNUD ${ }^{6}$, entre 1974 e 1976 colaborou para a implementação do Centro de ecodesenvolvimento do México, entre 1983 e 1987 foi diretor do programa das interfaces alimentação-energia da Universidade das Nações Unidas. Desde 1990 é assessor da UNESCO no Programa de Cooperação Sul-Sul, participou ativamente da preparação da Rio-92, e desde 1996 é membro da comissão para o Desenvolvimento Sustentável do Ministério de Meio Ambiente francês (MOURA, 2013.p.145). Ignacy Sachs ainda possui uma vasta contribuição literária.

\section{Ecodesenvolvimento e as dimensões da sustentabilidade}

Como anteriormente mencionado, as reflexões em torno dos elementos contidos no tema desenvolvimento sustentável remontam a década de 1950, no entanto, o surgimento do conceito é relativamente recente, datando de 1987 quando Gro Harlem Brundtland, presidente da Comissão Mundial sobre o Meio Ambiente e Desenvolvimento, apresentou os resultados do relatório "Nosso Futuro Comum" à Assembleia Geral da Organização das Nações Unidas - ONU (VEIGA, 2009). Tem como ponto central a ideia de um crescimento econômico eficiente e racional, que satisfaça as necessidades das gerações presentes sem comprometer o direito das gerações futuras em ter suas necessidades supridas. Antes do conceito de desenvolvimento sustentável virar moda, o termo ecodesenvolvimento, criado por Maurice Strong, foi bastante discutido, principalmente na década de 1970. Ignacy Sachs foi um dos autores que contribuíram com essas discussões ao reformular esse conceito e definir suas dimensões (CHACON, 2007.p.111).

Para ele, o ecodesenvolvimento significa um desenvolvimento socioeconômico equitativo e implica em escolher um processo de desenvolvimento que seja sensível ao meio

\footnotetext{
${ }^{5}$ Para obter maior apoio dos países em desenvolvimento com relação à Conferência de Estocolmo, Maurice Strong, então Secretário-Geral, realizou inúmeras viagens para encontrar-se pessoalmente com líderes do mundo em desenvolvimento e esclarecer qual direção ele pretendia dar à Conferência. Mas o fator determinante para obter o apoio da maioria dos países em desenvolvimento foi a sua decisão de convocar o Grupo de Peritos sobre Desenvolvimento e Meio Ambiente, que se reuniria em Founex, na Suíça, em junho de 1971 (LAGO, 2007).

${ }^{6}$ Comissão Econômica para a América Latina e o Caribe/Programa das Nações Unidas Para o Desenvolvimento.
} 
ambiente, reconhecendo sua devida importância como base de qualquer sistema vital ou econômico (CHACON, 2007.p121).

A preocupação com o desenvolvimento e o papel do homem dentro desse processo está presente em toda a obra de Sachs. O desenvolvimento visa à liberação da personalidade humana, de todos os homens e deveria apoiar-se, um dia, mais sobre o autocontrole das necessidades materiais pelo indivíduo, do que sobre um controle social do consumo (SACHS, 1986.p.28).

A ideia de que o desenvolvimento está ligado à esfera da ética e não exclusivamente ao campo econômico, para Sachs, é indispensável, bem como a necessidade de um planejamento como destaca CHACON (2007, p.120).

\begin{abstract}
Sachs ressalta a importância do planejamento, mas um planejamento realista e realizador. Isto é, para Sachs, o planejamento deve permitir o estudo sério e aprofundado das condições que envolvem um dado projeto que vise desenvolver um espaço em um certo tempo, ressaltando não só os trunfos possíveis, mas também todas as debilidades encontradas, permitindo, assim, a antecipação de falhas e não apenas promovendo um ótimo utópico. Além disso, um bom planejamento deve ser flexível, pois a realidade é dinâmica.
\end{abstract}

Para Sachs (1993.p.37), todo o planejamento de desenvolvimento precisa levar em conta, simultaneamente, as seguintes dimensões da sustentabilidade ${ }^{7}$ :

1. Sustentabilidade social, que se entende como a criação de um processo de desenvolvimento que seja sustentado por um outro crescimento e subsidiado por uma outra visão do que seja uma sociedade boa, onde a meta é construir uma civilização com maior equidade na distribuição de renda e de bens, de modo a reduzir o abismo entre os padrões de vida dos ricos e dos pobres.

2. Sustentabilidade econômica, que deve ser tornada possível através de uma alocação mais eficiente dos recursos, inclusive entre as nações e deve ser medida em termos macrossociais, e não apenas através do critério da rentabilidade empresarial de caráter microeconômico.

\footnotetext{
${ }^{7} \mathrm{O}$ autor acrescentaria, posteriormente, mais três dimensões: a sustentabilidade Ambiental, que trata do respeito em realçar a capacidade de autodepuração dos ecossistemas naturais; a sustentabilidade Política (Nacional), que trata da capacidade do Estado para implementar um projeto nacional, em um nível razoável de coesão social, pautado na democracia como apropriação universal dos direitos humanos; e a sustentabilidade Política (Internacional), pautada na prevenção de guerras, garantia da paz, pacto Norte-Sul de codesenvolvimento baseado no princípio da igualdade, proteção ao meio ambiente e na cooperação internacional (SACHS, 2009).
} 
3. Sustentabilidade ecológica, para alcançá-la deve-se usar de forma criativa, mas responsável, o potencial de recursos do planeta; limitar o uso de recursos não-renováveis e ampliar a utilização, de forma adequada, dos recursos renováveis; diminuir a poluição e aumentar a reciclagem; conscientizar para a limitação do consumo por países e indivíduos; aumentar as pesquisas para descobrir tecnologias limpas; normatizar, institucionalizar e instrumentar a proteção ao meio ambiente.

4. Sustentabilidade espacial, conseguida através de um equilíbrio entre as zonas rurais e urbanas, distribuindo melhor por estas as atividades econômicas e humanas.

5. Sustentabilidade cultural, que pretenda promover o desenvolvimento local, levando-se em conta os saberes locais.

Ciente das críticas, da polissemia e do uso indiscriminado que permeiam o conceito de desenvolvimento sustentável e de sustentabilidade $^{8}$, o presente trabalho destaca as contribuições de Sachs para a temática, enfatizando, principalmente, sua preocupação com o papel do homem nesse processo. Nesse sentido suscitaremos uma instigação reflexiva em torno da dimensão social da sustentabilidade proposta pelo autor.

\section{Não, não podemos}

Primeiro presidente negro em um país marcado pelo segregacionismo, o democrata Barack Obama foi eleito presidente dos Estados Unidos da América em 2008. Durante a campanha, o então senador, adotou uma variação do lema da United Farm Workers ${ }^{9}$ e transformou o "Yes, we can" em seu principal slogan. Sem pretensões políticas, este trabalho faz uso de uma versão negativa do lema de campanha do referido presidente para afirmar: Não, não podemos.

\footnotetext{
${ }^{8}$ Entre as principais críticas em torno do conceito de desenvolvimento sustentável, destacam-se as que afirmam ser excessivamente abrangente, não definir os limites do crescimento econômico, e as dificuldades para avaliar seus indicadores. Outras, afirmam que desenvolvimento sustentável e sustentabilidade são conceitos ideologicamente criados para reafirmar o sistema capitalista. Mais recentemente, teorias distinguem desenvolvimento sustentável de sustentabilidade, onde esta, se deferência do conceito anterior por não estar associada a um modelo desenvolvimentista.

9 "Yes, we can" é uma variação que tem origem no "Yes, it can", ou no espanhol "Si, si puede", que foi lema da luta dos trabalhadores do United Farm Workers (UFW - Sindicato dos Trabalhadores Rurais) dos EUA na década de 1970, quando os líderes sindicais César Chávez e Dolores Huerta fizeram uma greve de fome durante 25 dias para protestar por melhores salários e condições de trabalho para os trabalhadores das fazendas que produziam uvas e alfaces. "Yes we can: lema de campanha de Obama tem origem em greve". 2008. Disponível em: http://www.vermelho.org.br/. Acesso em 05 de abril de 2014.
} 
Não podemos admitir a desabilitação ${ }^{10}$ questionada por Sennett (2012.p.17) quando se refere ao fato de a sociedade moderna estar tornando ainda mais difícil a tarefa de cooperar, principalmente com aqueles que são diferentes. Desabilitação esta, pautada principalmente por motivos: materiais, caracterizados pelas desigualdades econômicas e consequentemente sociais; Institucionais, característicos do estímulo à competição, isolamento e auto-suficiência dos trabalhadores; e culturais, na tentativa de homogeneização do gosto conectando-se com a economia da cultura global de consumo (SENNETT, 2012.p.17-18).

As desigualdades econômicas se traduzem na experiência cotidiana em termos de distância social; a elite torna-se remota para a massa, restando pouco terreno comum entre as expectativas e lutas de um motorista de caminhão e as de um banqueiro. Distâncias dessa natureza muito justificadamente deixam indignadas as pessoas comuns; o pensamento e o comportamento do tipo nós-contra-eles são, nesse caso, uma consequência racional (SENNETT, 2012. p.18).

Para SANTOS (2008.p.19) "Há uma busca de uniformidade, ao serviço dos atores hegemônicos, mas o mundo se torna menos unido, tornando mais distante o sonho de uma cidadania verdadeiramente universal. Enquanto isso, o culto ao consumo é estimulado".

Não podemos insistir nos modelos de desenvolvimento transpostos criticados por Zaoual (2006), Chacon (2007) e pelo próprio Sachs (1993), que fracassam por não atenderem aos anseios das populações e pelo fato de refletirem receitas importadas que não consideram as especificidades locais, os sítios simbólicos de pertencimento (ZAOUAL, 2006), o que historicamente vem provocando o aumento da pobreza e o desperdício de recursos. Os fatos de experiência mostram que já não é mais possível conceber os processos de desenvolvimento como exportação de um "vulgar sistema econômico" de um espaço para outro, pois a diversidade de contextos, atrás da qual dissimulam-se questões de ética e de visões de mundo, é incontornável para todos aqueles que se esforçam em melhorar os conhecimentos práticos e teóricos no domínio do desenvolvimento (ZAOUAL, 2006.p.23).

Não podemos pensar e agir unicamente como homo economicus restritos ao caráter de produtor e consumidor, subtraídos dos aspectos das dimensões culturais da diversidade humana, visão marcadamente presente nas ciências econômicas pautadas por valores utilitaristas e mercantis (ZAOUAL, 2006.p.50), a ética neoliberal, ou ética de mercado, a qual Freire (2013) recusa-se a ser conivente propondo uma ética universal do ser humano.

\footnotetext{
${ }^{10}$ Sennet (2012.p.19) afirma que o termo desabilitar, origina-se da substituição de homens por máquinas na produção industrial na medida em que as máquinas complexas foram tomando o lugar do trabalho manual. Para ele essa desabilitação vem ocorrendo também no campo social quando as pessoas perdem a capacidade de lidar com as diferenças.
} 
Não podemos persistir com a ideia de que o homem é auto-suficiente, superior aos demais seres vivos e aos seus semelhantes, fomentada pelo atual modelo de desenvolvimento, pois segundo Chacon (2007.p.56) para substituir os conflitos e resgatar a possibilidade do encontro o primeiro esforço que o homem deve fazer é se ver como espécie. Não sendo admissível, portanto, toda e qualquer forma de discriminação.

Para Freire (2013.p.37), a prática preconceituosa de raça, de classe, de gênero ofende a substantividade do ser humano e nega radicalmente a democracia, e quão longe dessa democracia nos achamos quando vivemos a impunidade dos que matam meninos nas ruas, dos que assassinam camponeses que lutam por seus direitos, dos que discriminam os negros, dos que inferiorizam as mulheres. Quão ausentes da democracia se acham os que queimam igrejas de negros porque, certamente negros não tem alma. Negros não rezam. Com sua negritude, os negros sujam a branquitude das orações (FREIRE, 2013.p.37).

Não podemos acreditar que os problemas ambientais serão solucionados e o desenvolvimento sustentável será alcançado se desprezarmos as dimensões da sustentabilidade mencionadas por Sachs (1993.p.37): Social, que viabiliza uma sociedade mais justa, diminuindo as diferenças entre ricos e pobres; Econômica, que leva a uma alocação mais eficiente de recursos devendo ser medida em termos macrossociais, e não apenas no âmbito das empresas; Ecológica, devendo-se, entre outras coisas, limitar o uso de recursos não renováveis, diminuir a poluição e investir em pesquisas para descobrir tecnologias limpas; Espacial, conseguida através de um equilíbrio entre as zonas rurais e urbanas, distribuindo melhor por estas as atividades econômicas e humanas; Cultural, promovendo o desenvolvimento local, levando-se em conta os saberes locais.

Não podemos concordar com a ideia propagada de que nesses tempos de globalização econômica o papel do Estado seja irrelevante para a promoção do desenvolvimento, pois, para Santos (2008.p.19) fala-se muito, e com insistência, na morte do Estado, mas o que estamos vendo é seu fortalecimento para atender aos reclamos da finança e de outros grandes interesses internacionais, em detrimento dos cuidados com as populações cuja vida se torna cada vez mais difícil.

CHACON (2007, p. 74) acrescenta:

Mesmo com a desarticulação de várias estruturas do Estado promovida sob a égide do neoliberalismo, o Estado continua como principal ente promotor do desenvolvimento. A tentativa de impor o mercado como ente regulador das relações 
sociais, principalmente a partir dos anos 1980, provocou um grande abalo no Estado do Bem-Estar, concebido com base nas ideias keynesianas, após a II Guerra Mundial, que entrou em crise todo o mundo. Contudo, esse movimento, que também se dizia modernizador, não foi suficiente para enfraquecer totalmente o Estado. Por outro lado, o fracasso das políticas neoliberais fez com que as forças mundiais do capitalismo se voltassem novamente para o Estado, dessa feita com o intuito de reforçar seu papel de reprodutor da ideologia capitalista e de mantenedor da ordem.

Não podemos aceitar que, como diz a música, as pessoas que se enrolam nos jornais não são mais notícias ${ }^{11}$, e encarar a pobreza, a fome e o desemprego com naturalidade, chocando-se apenas, e às vezes nem assim, quando há uma violência física contra um determinado grupo ou indivíduo e que desperte o interesse da imprensa ${ }^{12}$. Pois hoje, a produção maciça de pobreza aparece como um fenômeno banal que impõe-se e explica-se como algo natural e inevitável. Mas é uma pobreza produzida politicamente pelas empresas e instituições globais, que, de um lado, pagam para criar soluções localizadas, parcializadas, segmentadas, em diferentes partes do mundo, financiando programas de atenção aos pobres, atacando, funcionalmente, manifestações da pobreza, enquanto estruturalmente se cria a pobreza ao nível de mundo (SANTOS, 2008.p.73).

Para FREIRE (2013, p. 21):

A ideologia fatalista, imobilizante, que anima o discurso neoliberal anda solta no mundo. Com ares de pós-modernidade insiste em convencer-nos de que nada podemos contra a realidade social que, de histórica e cultural, passa a ser ou a virar "quase natural". Frases como "a realidade é assim mesmo, que podemos fazer?" ou "o desemprego no mundo é uma fatalidade do fim do século" expressam bem o fatalismo desta ideologia e sua indiscutível vontade imobilizadora.

Não podemos compactuar com a ideologia de uma minoria dominante que, segundo Freire (2013) tenta atribuir a culpa pela miséria à preguiça popular, a mestiçagem ou à vontade punitiva de Deus, um determinismo social, e não como uma violência cometida contra estes. Para ele, é importante ter sempre claro que faz parte do poder ideológico dominante a incultação nos dominados da responsabilidade por sua situação, para assim, sentirem-se culpados por se acharem nesta ou naquela situação desvantajosa. Pessoas assim fazem parte das legiões de ofendidos que não percebem a razão de ser de sua dor na perversividade do sistema social, econômico e político em que vivem, mas na sua incompetência e enquanto sentirem assim, pensarem assim e agirem assim, reforçam o poder do sistema e se tornam coniventes da ordem desumanizante (FREIRE, 2013.p.81).

\footnotetext{
${ }^{11}$ NÓS, Nenhum de. Jornais. Acústico e ao vivo. Porto Alegre: polygram, 1994. Faixa 11. CD.

12 TÚLIO, Silvio. "Grande Goiânia registra a $17^{\mathrm{a}}$ morte de morador de rua em cinco meses". 2013. Disponível em: http://g1.globo.com/goias/noticia/2013. Acesso em 07 de abril de 2014.
} 
Não podemos acatar a naturalização da violência, e desprezar a concepção de que esta foi e está sendo construída social e historicamente (NASCIMENTO; MATOS, 2010) bem como julgar que os problemas referentes às suas diversas manifestações sejam resolvidos unicamente com ações punitivas, segmentadas e isoladas, que não levem em consideração os questionamentos feitos até aqui.

Fala-se hoje, muito em violência, e é geralmente admitido que é quase um estado, uma situação característica do nosso tempo. Todavia, dentre as violências de que se fala, a maior parte é sobretudo formada de violências funcionais derivadas, enquanto a atenção é menos voltada para o que preferimos chamar de violência estrutural, que está na base da produção das outras e constitui a violência central original. Por isso, acabamos por apenas condenar as violências periféricas particulares (SANTOS, 2008. p.55).

Não podemos confundir crescimento econômico com desenvolvimento, pois o primeiro ocorre em termos eminentemente econômicos, detectado pelo aumento da quantidade produzida em um determinado período de tempo, e em um dado espaço territorial; enquanto o segundo se manifesta pela distribuição equitativa dos resultados do crescimento para toda a população (FURTADO, 1974, Apud CHACON, 2007.p.114). E, de nada nos adiantará sermos a quinta economia do planeta em 2017 se isso for atingido às custas do extermínio, da criminalização dos jovens, da destruição ambiental e da negação da cidadania a todos e todas (ROSENO, 2013, Apud NASCIMENTO; PETROLA, 2014.p.79).

\section{Considerações finais}

Ao longo do diálogo com os autores citados e do que foi mencionado até o presente, algumas considerações devem ser elencadas para que não se tenha uma compreensão equivocada da proposta deste trabalho.

Em primeiro lugar, é fundamental perceber que se faz necessário, e urgente, uma mudança radical nas condições do modelo econômico, social e político vigente, de modo que a centralidade das ações passe a ser localizada no homem, e não mais ocupada pelo dinheiro em estado puro, sustentado por uma informação ideológica que distorce o sentido de vida (SANTOS, 2008). Sendo assim, a primazia do homem, não é incompatível com o respeito à natureza, desde que se substitua a lógica de que qualidade de vida é sinônimo de quantidade de coisas, e que as relações de poder e as escolhas individuais deixem de ser prioridades. 
Portanto, é preciso deixar claro que este trabalho não propõe uma ruptura entre as dimensões social e ecológica da sustentabilidade onde a primeira tenha que ser privilegiada em detrimento da segunda. Pelo contrário, pretende-se aqui enfatizar a compreensão de Sachs de que para uma real tentativa de alcance do desenvolvimento sustentável, ou ecodesenvolvimento, todas as dimensões mencionadas anteriormente devem ser privilegiadas simultaneamente, bem como suas variáveis. Tendo em vista o fato de que justamente o não respeito a essa simultaneidade de valores tem comprometido historicamente os projetos e políticas que tem como objetivo promover o desenvolvimento.

Em segundo lugar, quando se destaca questões referentes à dimensão social neste artigo, é possível que, assim como afirma Freire (2013) algum leitor ou leitora, mesmo que não totalmente convertido ao "pragmatismo" neoliberal, mas já por ele tocado, classifique-o como utópico, inviável, entre outras denominações. Para Camargo (2012), o real desenvolvimento sustentável, que é hoje considerado mito ou utopia, pode vir a ser - muito mais rapidamente do que se possa esperar - a única opção viável e segura para alcançar um projeto coerente de civilização. E em resposta ao fatalismo, ao reducionismo e a desumanização, a experiência empírica da sociedade aponta para um número cada vez maior de pessoas inconformadas e insatisfeitas com o atual modelo socioeconômico, onde os 85 mais ricos possuem rendas correspondentes a 3,57 bilhões de pessoas $^{13}$, e é preciso lembrar que a insatisfação com o status quo e a esperança sempre estiveram ligados à gênese das grandes revoluções e insurreições ao longo da história humana.

\section{Referências}

BOFF, Leonardo. “O tempo das utopias mínimas viáveis”. 2014. Disponível em: http://leonardoboff.wordpress.com/2014/05/09/o-tempo-das-utopias-minimas-viaveis/. Acesso em 05 de junho de 2014.

CAMARGO, Ana Luiza de Brasil. Desenvolvimento sustentável: dimensões e desafios. Campinas: Papirus, 2012.

CHACON, Suely Salgueiro. O Sertanejo e o caminho das águas: políticas públicas, modernidade e sustentabilidade no semiárido. Fortaleza: Banco do Nordeste do Brasil, 2007.

FREIRE, Paulo. Pedagogia da autonomia: saberes necessários à prática educativa. Rio de Janeiro: Paz e Terra, 2013.

${ }^{13}$ ONG - Oxfam intermón, Janeiro de 2014 em Davos (BOFF, 2014). 
LAGO, A. A. C. do. Estocolmo, Rio, Joanesburgo ～- O Brasil e as Três Conferências Ambientais das Nações Unidas. Brasília: Instituto Rio Branco; Fundação Alexandre de Gusmão, 2007 (276 p.).

MOURA. Valquíria Soares de. Caminhos para o desenvolvimento sustentável. Boletim de geografia UEM. Revista Produção on-line. Vol. 31. Maringá: Universidade Estadual de Maringá: Departamento de Geografia. $N^{\circ} 1$ (2013). Disponível em: http://www.periodicos.uem.br/ojs/index.php/BolGeogr/issue/view/694.

NASCIMENTO. Verônica Salgueiro do; PETROLA, Domingos Arthur Feitosa. Educar para a paz e para a sustentabilidade: construindo caminhos para outro mundo possível. Revista NAU Social. Revista Produção on-line. Vol. $5 \mathrm{~N}^{\mathrm{o}} 8$ (2014). Salvador: Escola de Administração da Universidade Federal da Bahia. Disponível em: www. periodicos.adm.ufba.br/index.php/rs/article/view/404.

Verônica Salgueiro do; MATOS, Kelma S. Lopes. Articulando saberes da educação para a paz e educação ambiental: o anúncio de uma nova era. Disponível em: http://desenvolvimento-regional-sustentavel.blogspot.com/2010.12/arquivo-veronicasalgueiro-e-kelma-matos.html.

NÓS, Nenhum de. Jornais. Acústico e ao vivo. Porto Alegre: polygram, 1994. Faixa 11. CD.

PEREIRA. Luiz Carlos Bresser. Ignacy Sachs e a nave espacial Terra. Revista de economia e política. Revista Produção on-line. Vol. 33. São Paulo. No 2 (131) 2013. Disponível em: http://www.scielo.br/scielo.php?pid=S0101-31572013000200010\& script =sci_arttext.

SACHS, Ignacy. Caminhos para o Desenvolvimento Sustentável. Rio de Janeiro: Garamond, 2009.

Ecodesenvolvimento: Crescer sem destruir. Tradução de E. Araujo. São Paulo: Vertice, 1986.

Estratégias de transição para o século XXI. In: BURSZTYN, M. (Org.) Para pensar o desenvolvimento sustentável. 1.ed. São Paulo: Brasiliense, 1993.

SANTOS, Milton. Por uma outra globalização - do pensamento único à consciência universal. Rio de Janeiro: Record, 2008.

SENNETT, Richard. Juntos: Os Rituais, os Prazeres e a Política da Cooperação. $1^{\text {a }}$. ed. Rio de Janeiro: Record, 2012.

TÚLIO, Silvio. “Grande Goiânia registra a 17 morte de morador de rua em cinco meses”. 2013. Disponível em: http://g1.globo.com/goias/noticia/2013. Acesso em 07 de abril de 2014.

VEIGA, José Eli da. Como monitorar o desenvolvimento sustentável? A resposta da Comissão Stiglitz Sen-Fitoussi (CMEPSP) de junho 2009. São Paulo, 14 de junho de 2009.

ZAOUAL, Hassan. Nova economia das iniciativas locais: uma introdução ao pensamento pós-global. Rio de Janeiro: DP\&A: Consulado Geral da França: COPPE/UFRJ, 2006. 